\title{
In situ static performance assessment of mine mesh
}

\author{
RK Whiting Independence Group, Australia
}

\begin{abstract}
Welded steel wire mesh is commonly used for ground control as a major component of the support scheme. Plates attached to rockbolts are the most common surface fixture and mesh is subjected to a wide range of loading conditions, yet the measurement of in situ load-displacement characteristics for surface support mesh are poorly defined.

A campaign of in situ static testing at Independence Long nickel mine has collected force-displacement characteristics of two different mine mesh configurations. A standard test method is proposed using a machine designed and manufactured in house from readily available hardware.

Testing is conducted in situ with a range of bolt spacing and relative loading locations similar to real-world application.

Mesh sheet configurations with additional and thicker diameter wire strands to accommodate superior load transfer and seismic damage capacity have been developed and tested. These sheets were compared with standard mesh sheets with $100 \mathrm{~mm}$ aperture.

Data shows standard mesh sheets can provide confinement to the rock mass at displacements that can be greater than $400 \mathrm{~mm}$. Peak load values of up to $60 \mathrm{kN}$ are generated using standard mesh. These values are even higher for high capacity 'seismic mesh', however, the loading response for all configurations is sensitive to a range of factors such as the location of installation in the drive profile, the bolt spacing, and interaction and overlap with other sheets.
\end{abstract}

Keywords: in situ test, mesh test, surface support, mesh, capacity, seismic mesh

\section{Introduction}

Independence Long is an ageing nickel mine operating at approximately 1,000 $\mathrm{m}$ depth in the Kambalda region of Western Australia. Strainburst and seismic hazard management are a core focus of the business to ensure safe and sustainable operation. A range of ground support schemes are applied throughout the mine and implemented dominantly according to seismic hazard.

The purpose of this paper is to present results to date on an in situ mesh test program. In addition to testing the modified strand mesh against standard mesh in situ results will capture differences due to irregularities in:

- Mesh installation geometry.

- Installation location within mine drive profile.

- Installed load of rockbolts.

- Loading location in sheet relative to the nearest edge.

\section{Motivation for conducting a test program}

A series of damaging seismic events during 2015 highlighted a weakness in the standard and lower level dynamic support schemes used onsite. Friction bolt with mesh support schemes were observed to fail regularly at the link between the mesh and the surface plate of the friction bolt (Figure 1). Mesh strands were prone to rupturing and pulling over the intact bolt and plate fixture to allow the mesh sheets to separate at the overlap, thus allowing ejection, shakedown and unravelling of mobilised rock. 


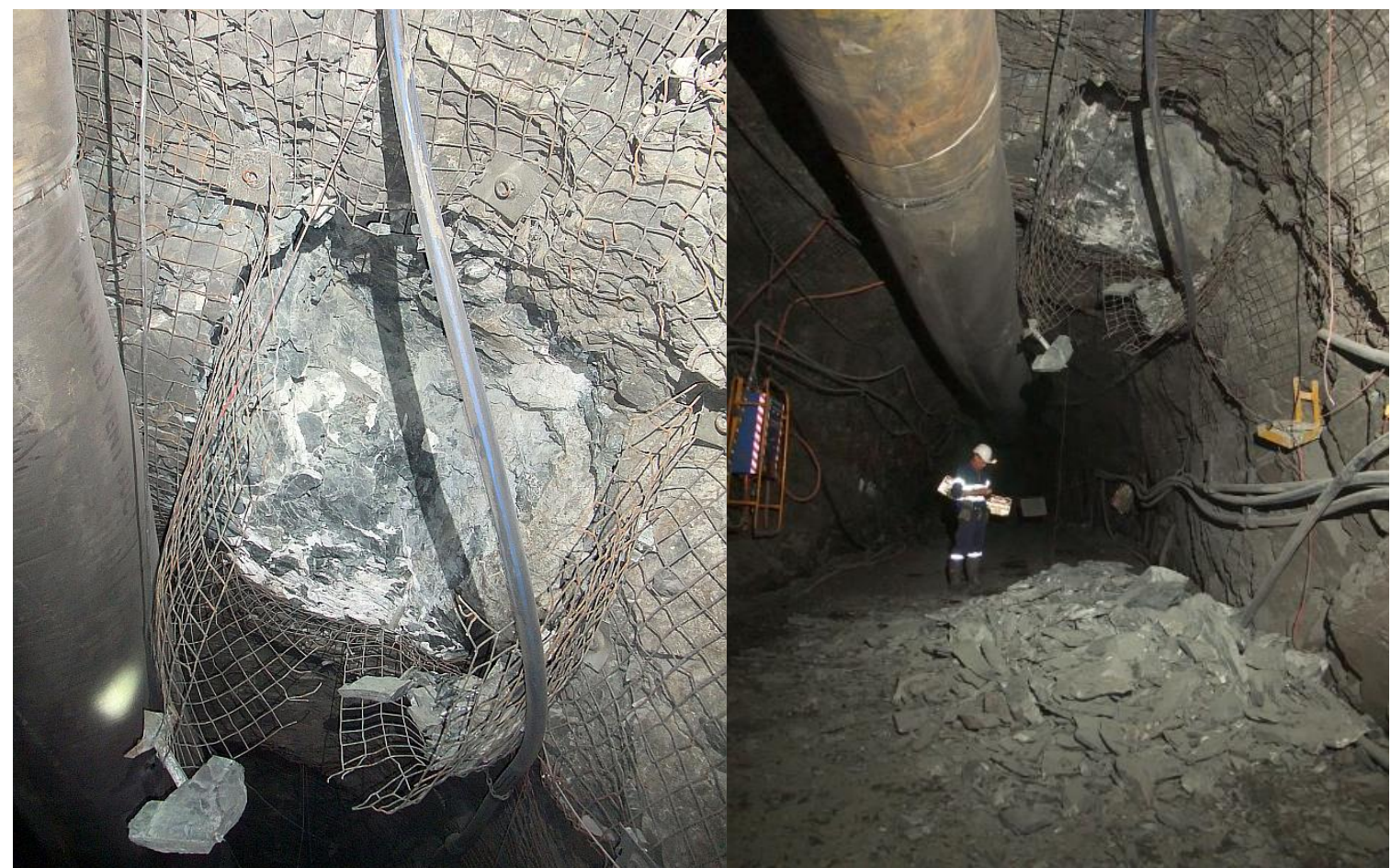

Figure 1 Seismic damage mobilises rock behind the mesh to overload the support scheme (left). Note the two adjacent mesh sheets have parted at the overlap location. Rupture of strands and/or the surface plate fixture occur as the mesh pulls over the plate. This allows release and unravelling of rock from behind the mesh

Some of the failure observations were in areas not reasonably expected to be rated with any significant seismic risk and with no local event history (such as ore access drives proximal to decline).

Although an infrequent occurrence, the spatial and temporal unpredictability of seismic damage meant an improved management approach was justified. Adopting blanket installation of high energy absorption support schemes throughout the entire operation was not necessary, nor is it practical or financially viable. The approach selected was to incrementally improve the weak link in the support scheme - the mesh - to improve the overall scheme capacity.

Alternative mesh configurations were investigated with additional strands or increased strand diameters placed to provide improved resistance to rupture and tearing around plates.

Mesh manufacturers Australian Steel and Wire provided guidance on fabrication options and product physical properties such as product weight, steel grade and strand diameter options. Operational aspects impacted by changes in the mesh included:

- Heavier mesh sheet weights - a concern for manual handling. Standard sheet weight $=31 \mathrm{~kg}$, modified sheet weight $=35.2 \mathrm{~kg}$ for $3 \times 2.4 \mathrm{~m}$ sheet ( $14 \%$ increase).

- Need for charge up operators to cut mesh with bolt cutters - increasing strand diameters make this difficult. This has been managed on site with a set of compact hydraulic bolt cutters of up to $8 \mathrm{~mm}$ capacity.

The sheet selected for use is shown in Figures 2 and 3. It has 14\% increased mass on standard and additional strand coverage at all common bolt locations. The only modification to longitudinal strands is the addition of $2 \times 6.3 \mathrm{~mm}$ wires (four in total) at $100 \mathrm{~mm}$ in from the outer edges of the sheet. The cross wires use only $5.6 \mathrm{~mm}$ strands with additional strands placed to provide additional capacity at bolt/plate locations. Both 8 and $6.3 \mathrm{~mm}$ extra strand variants have been manufactured and trialled. This paper presents only data from the $6.3 \mathrm{~mm}$ extra strand configuration. 

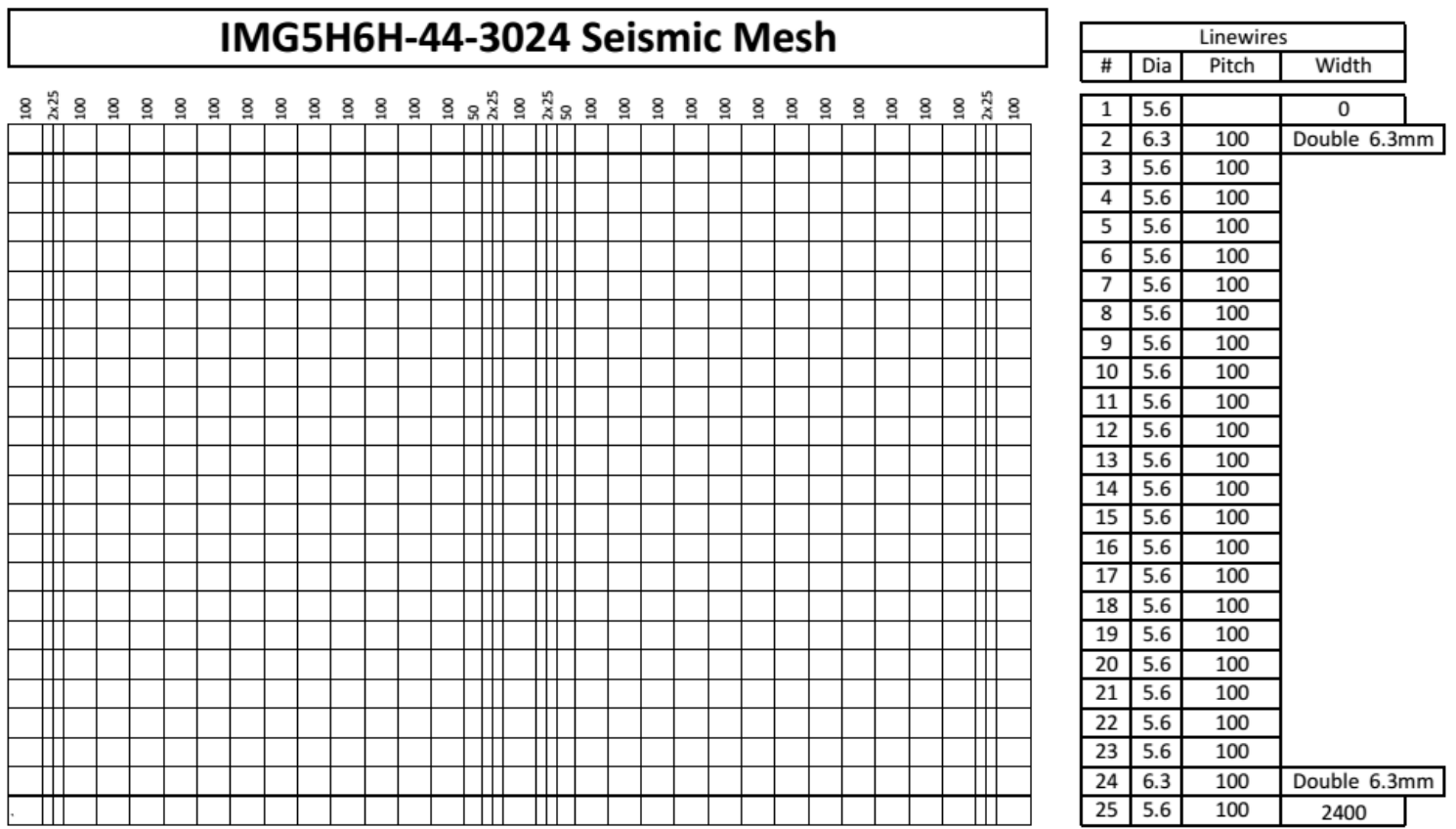

Figure 2 'Seismic mesh' configuration showing additional cross wires, longitudinal wires and increased strand diameter

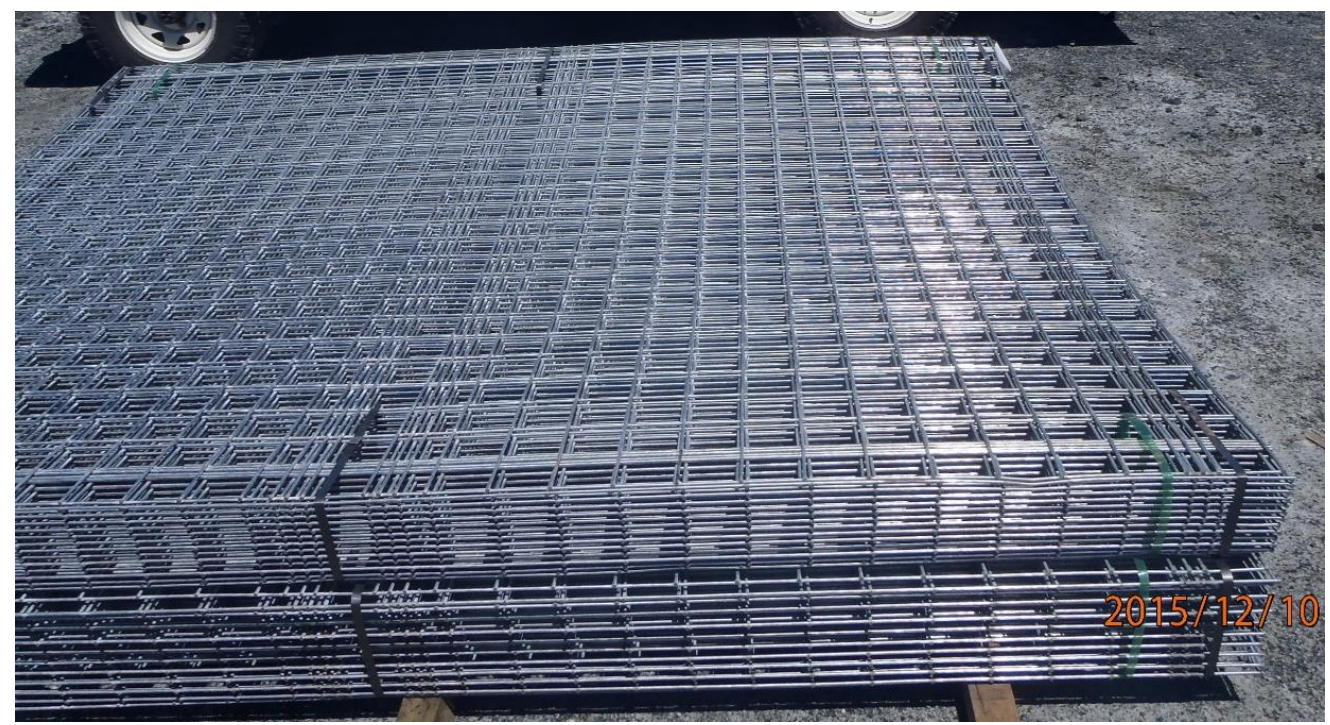

Figure 3 'Seismic mesh' delivered to site showing additional cross wires

\section{Conventional laboratory based test methods}

Both static and dynamic loading behaviour of welded wire mesh under laboratory conditions is well documented (Thompson et al. 1999; Morton et al. 2007; Player et al. 2008; Tannant 1995; Dolinar 2006). The product is widely used in ground support for underground mines yet the in situ load-displacement characteristics are poorly defined.

A program of static in situ mesh testing was formulated to improve knowledge and understanding of in situ mesh performance. A static test program was adopted as an appropriate first step, easily achievable, and without the complexities of dynamic testing. It is certain that static and dynamic mesh performance will differ.

While it is accepted that neither laboratory nor in situ test methods replicate performance under real world loading conditions, observations at Long nickel mine do bear strong resemblance to loading conditions simulated in this test programme (Figure 4). 


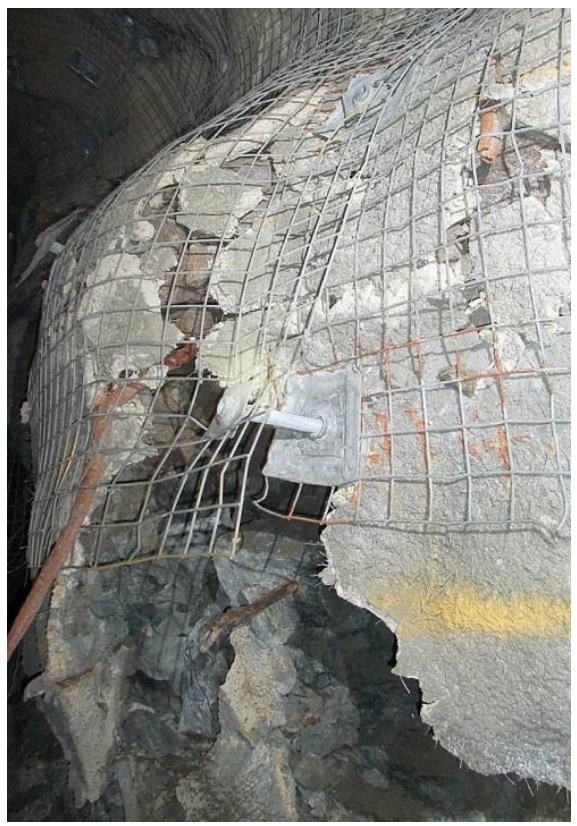

Figure 4 Bulking behaviour of mesh at Long shaft Nickel Mine

\section{$4 \quad$ Methodology}

\subsection{In situ test method and equipment}

The 'Meshmaster 1000' (Figure 5), as it is affectionately named, was created onsite by Lee Horan. A dual acting hydraulic ram sourced from a jumbo drill was adapted to mount to a standard pull collar mounting as used for quality control testing of friction bolts. A high pressure hydraulic pump was used to power the cylinder with up to approximately $70 \mathrm{MPa}(10,000 \mathrm{psi})$.

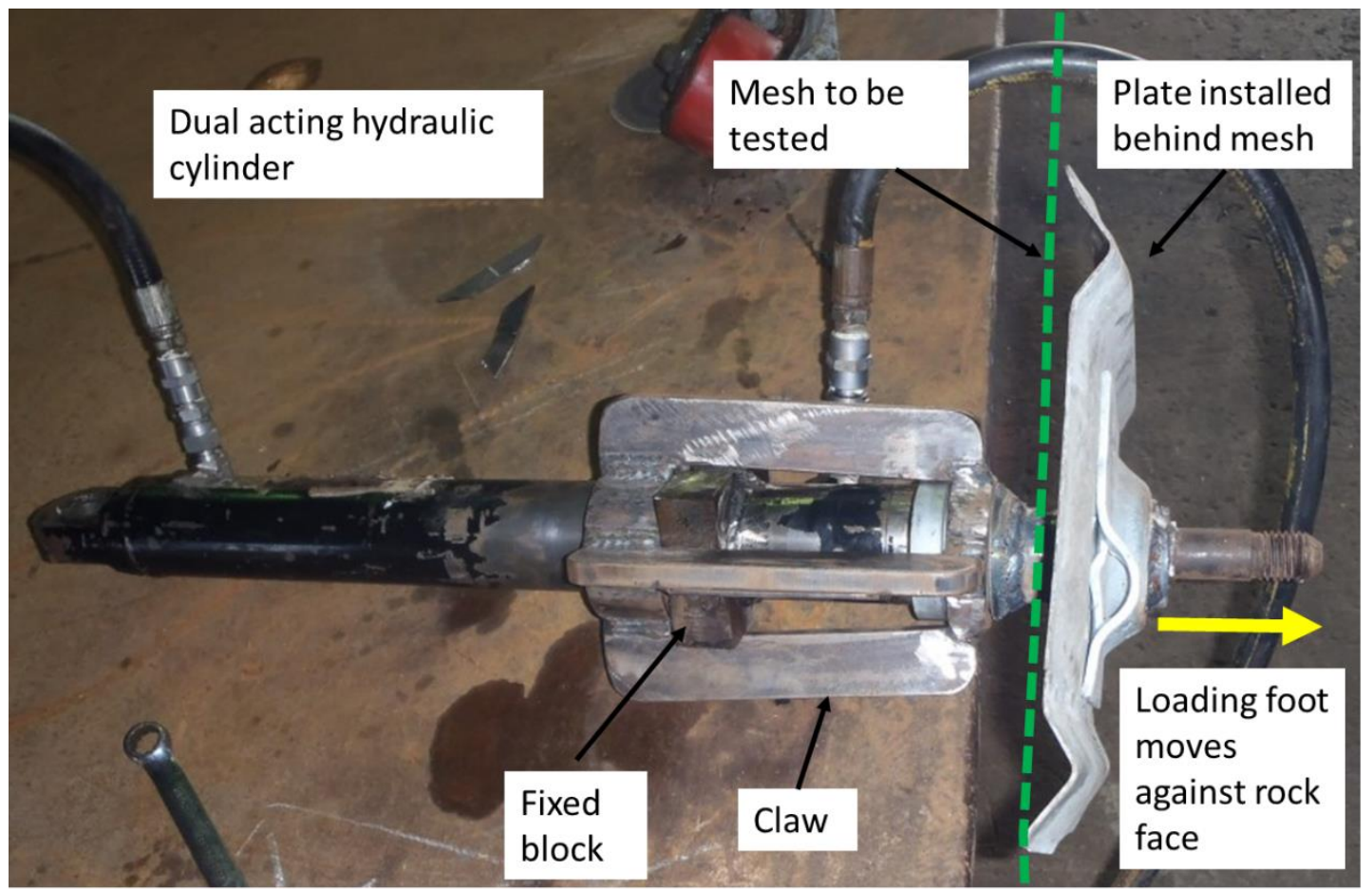

Figure 5 Meshmaster 1000 test rig built on site at Long nickel mine 
Mesh test plates were manufactured by using a standard friction bolt plate of $300 \times 280 \mathrm{~mm}$ with a welded pull test collar fitted (Figure 6). Plates were then installed at the desired test location - either a dice 5 or overlap position, before mesh was installed with $2.4 \mathrm{~m}$ friction bolts.

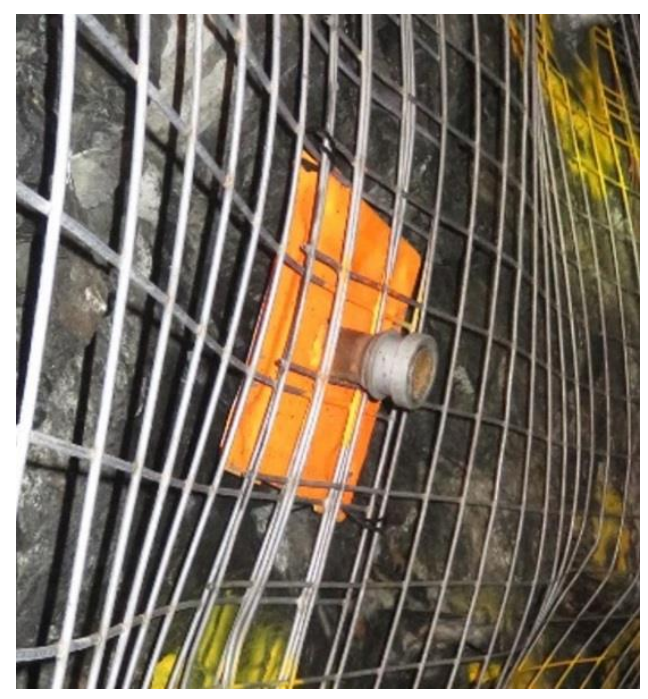

Figure 6 Test plate installed

The test rig attaches to the pull collar and drives a steel loading foot through the centre of the test plate to bear against the rock surface (Figure 7). When the stroke length limit of the ram $(400 \mathrm{~mm})$ is reached, the ram is reset and an extension bar of a suitable length is fitted to the loading foot. The test then continues from as near as practically possible to the previous load measurement. A typical test takes about 45 minutes to one hour to complete.

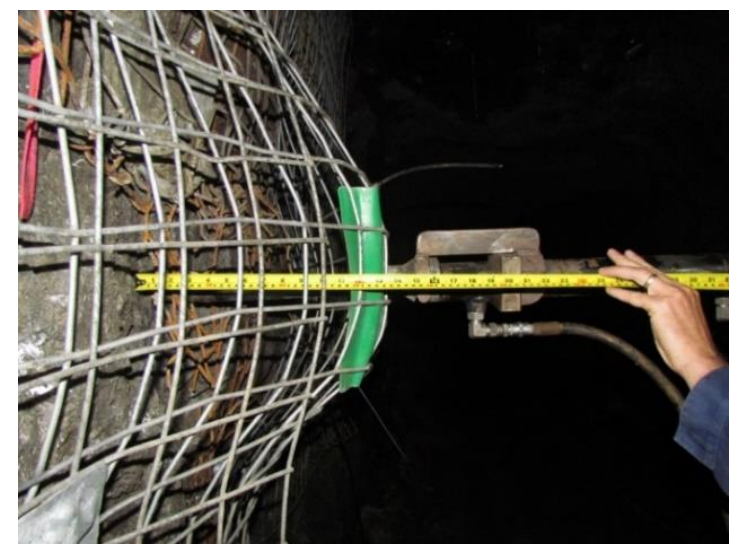

Figure 7 Mesh test in progress

Loading pressures imposed are measured incrementally throughout the test cycle, typically at stages of $20 \mathrm{~mm}$ displacement. Early testing used an analogue gauge set, allowing only instantaneous pressures to be recorded. Later tests used a digital gauge with memory function allowing instant measurements and maximum pressure measurement within a load cycle.

\subsection{Test configuration}

Extending the hydraulic cylinder pulls the test plate against the underside of the mesh. The mesh stretches as displacement increases and the plate starts to bend at higher loads. This configuration approaches the real world interaction of the bolt, plate and mesh system where the mesh becomes loaded by bulking or squeezing processes. The area tested is defined by the bolt spacing and configuration of the adjacent bolts surrounding the test plate. The dice 5 pattern (Figure 8 ) tests a nominal 1.4 square metre area. 


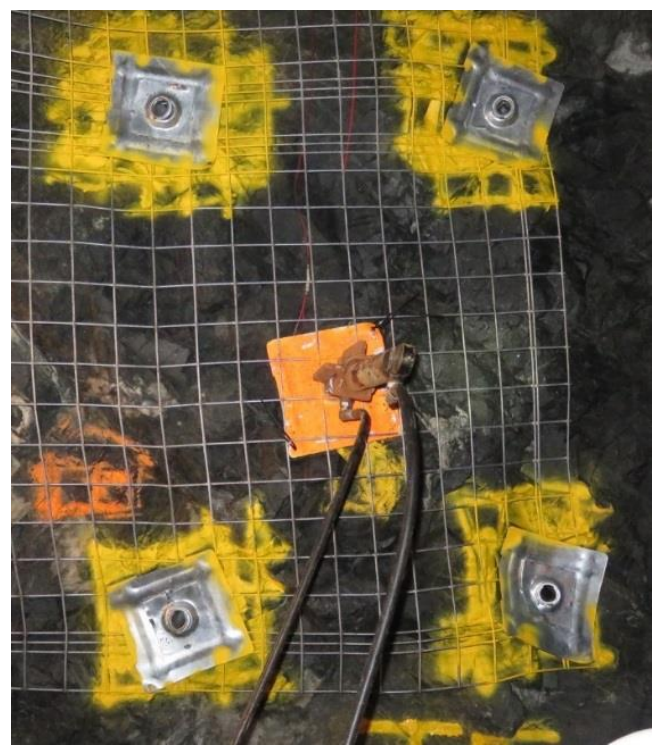

\section{Figure 8 Dice 5 test location}

The variables tested to date are:

- Location in drive profile.

- Walls - relatively flat surface.

- Shoulder - concave surface.

- Mesh type.

○ Seismic.

- Standard.

- Test position within bolting pattern.

- Sheet overlap position - test plate located at the overlap of two mesh sheets (Figure 9). The test is conducted in line between two bolts with nominal spacing of 1.1 or $1.3 \mathrm{~m}$ depending on sheet orientation.

- Dice 5 position - test place located in centre point of four bolts (Figure 8). Nominal bolt spacing of $1.1 \times 1.3 \mathrm{~m}$ rectangular pattern (1.4 square metre area).

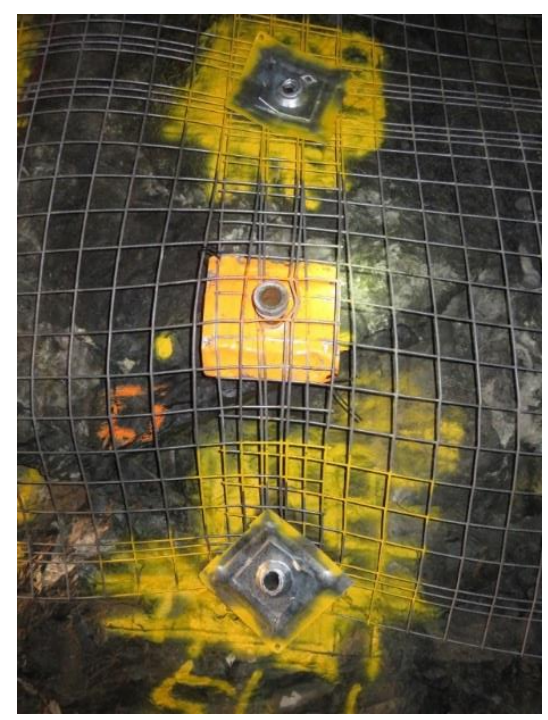

Figure 9 Overlap test location 


\subsection{Geometry of test panels}

Sheets were installed with longitudinal, larger diameter wires oriented along the length of the drive, and on the outer side (drive side) of the sheet (Figure 10). Mesh overlaps therefore include the large diameter dual wires on each side of the rockbolts (Figure 11).

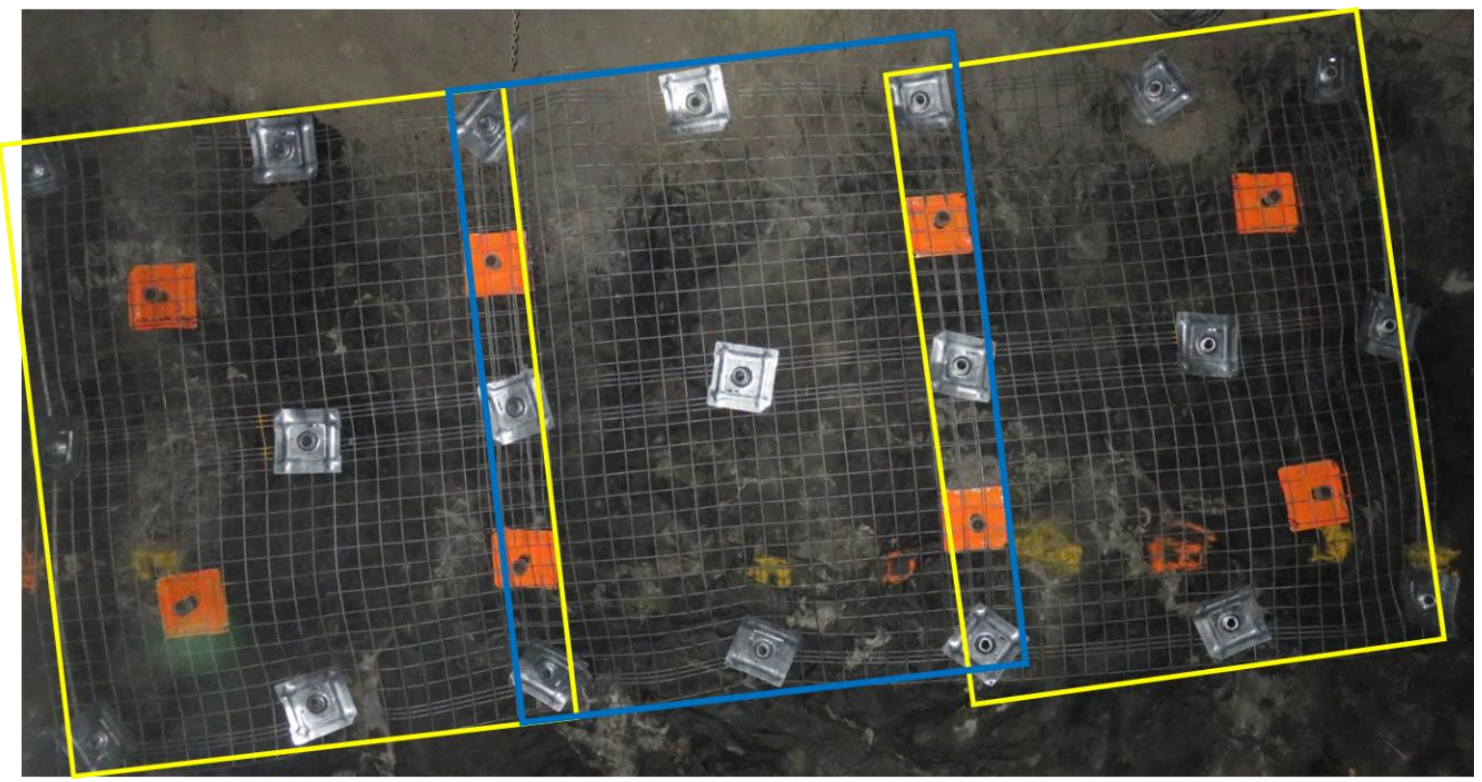

Figure 10 Typical layout of mesh sheets showing longitudinal wires forming overlap between sheets

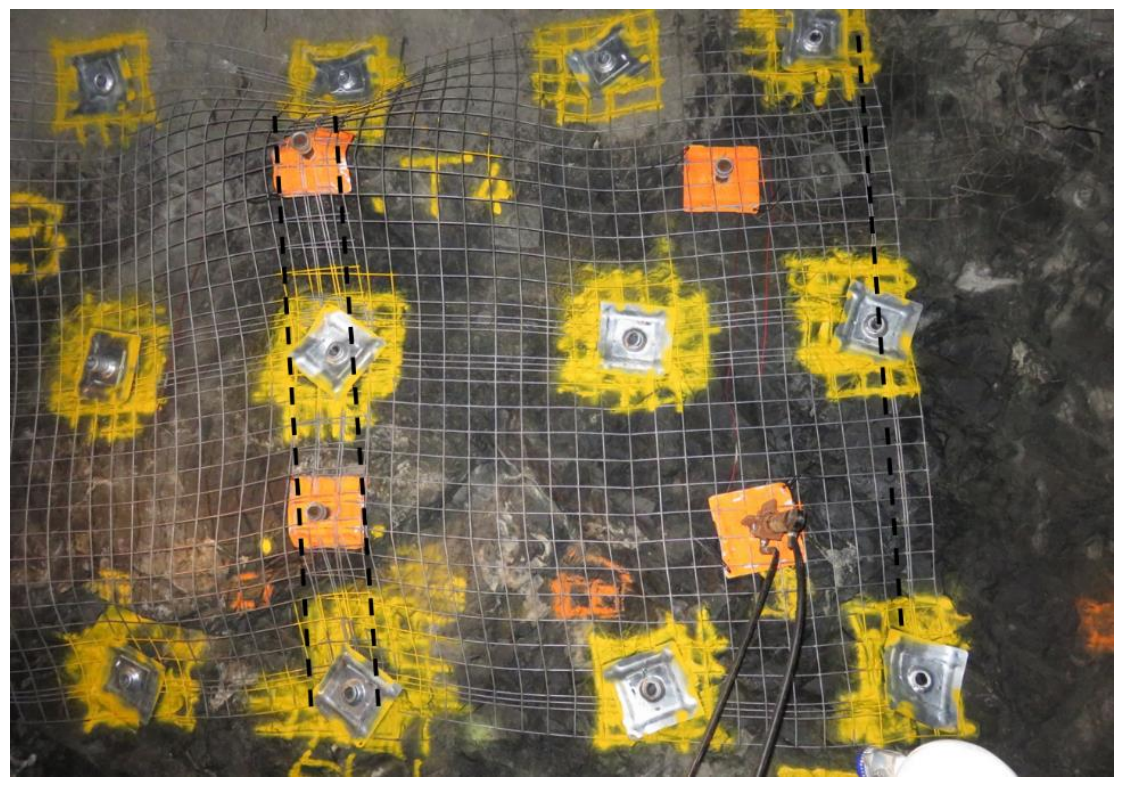

Figure 11 Rockbolts are placed between two lines of larger cross-section wires in longitudinal direction

\section{$5 \quad$ Results}

The results presented show the full test cycle including loading beyond strand or weld rupture. The cyclical load and unload process has been retained in the dataset as it is considered relevant to the discussion. Many laboratory tests show only progressive peak loads so the presentation may not be directly comparable. Some laboratory tests also end testing at the first rupture point due to change in system force-displacement behaviour beyond peak loads.

It is observed that system behaviour is not consistent beyond the peak loads, however, the data is retained in this analysis as the support scheme still provides some functionality beyond peak load. 


\subsection{Dice 5 configuration tests on wall}

\subsubsection{Standard mesh}

Figure 12 shows standard mesh force-displacement performance for installations on a drive wall. Standard mesh and seismic mesh results are displayed in cool and hot colours respectively.

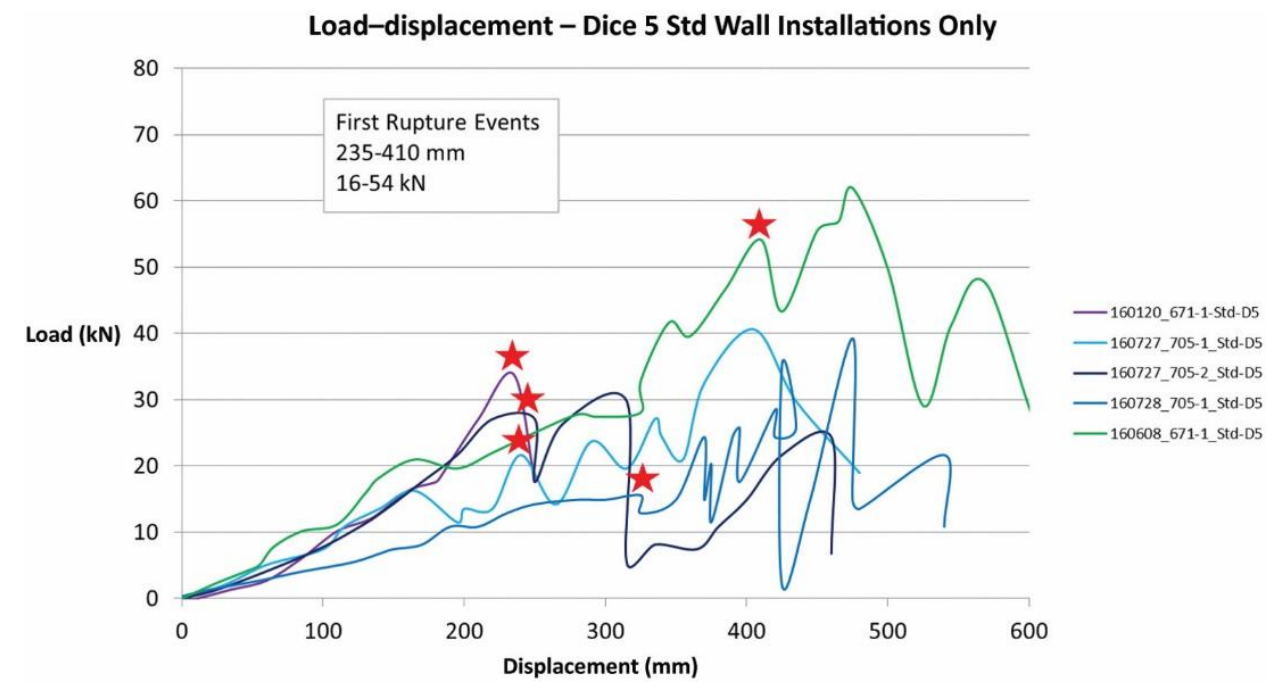

Figure 12 Load-displacement for standard mesh tests in dice 5 position. Note red stars are rupture locations (strand or weld rupture not differentiated), however, these were not always identifiable during a test

Some general observations are:

- A constant load increase per unit displacement observed up to $250-300 \mathrm{~mm}$ at which point first strand ruptures can be expected.

- First strand ruptures occur within a load range of 16-54 kN.

- Load per unit displacement increases beyond $300 \mathrm{~mm}$ and is characterised by multiple load and unload cycles as strands rupture or slip beneath the retaining plate.

- Peak loads achieved range from 30-62 kN at displacements in the range of 400-500 mm.

- Strand and weld rupture locations were recorded throughout the test cycles where possible. Ruptures were not always identifiable during a test where they were obscured by the surface plate fixture. It was therefore difficult to differentiate the rupture type. The data therefore shows undifferentiated rupture points.

\subsubsection{Seismic mesh}

Figure 13 shows seismic mesh force-displacement performance for installations on a drive wall.

- A constant load increase per unit displacement is observed at displacements of 250-350 mm.

- First strand ruptures can be expected at similar displacements but significantly higher loads than the standard mesh 32-54 kN.

- Progressive slip is common at displacements below $300 \mathrm{~mm}$ where mesh pulls gradually in a lateral direction below the plate fixture. Beyond this point a stepped type sudden slip becomes more common.

- Average load increase per unit displacement remains constant beyond $300 \mathrm{~mm}$, but is erratic and characterised by multiple load and unload cycles as strands rupture or slip beneath the retaining plate.

- Peak loads achieved range from 44-67 kN at displacements of $380-500 \mathrm{~mm}$. 


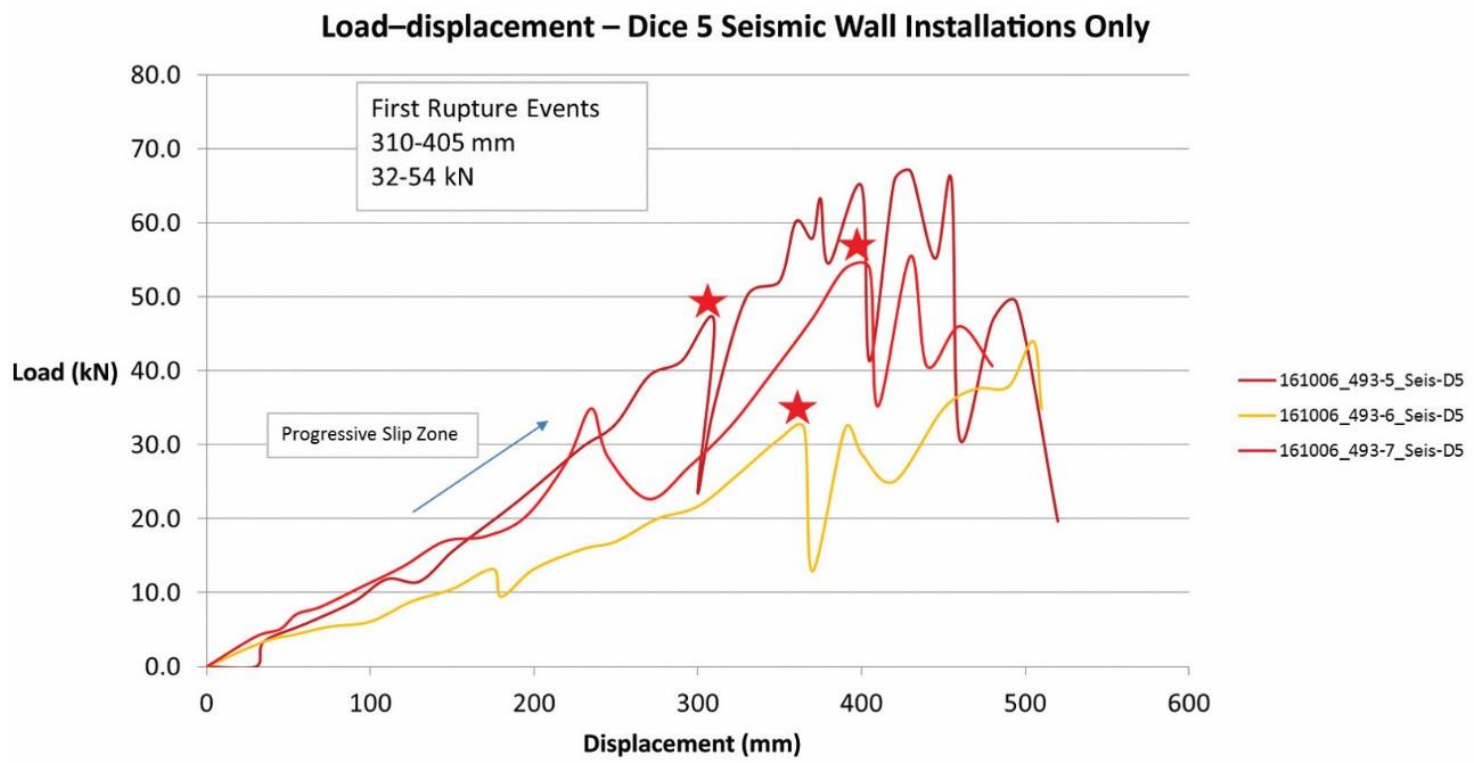

Figure 13 Load-displacement for seismic mesh tests in dice 5 position. Note red stars are rupture locations (strand or weld rupture not differentiated)

\subsection{Peak loads of standard and seismic mesh}

Both dice 5 seismic and standard sheets have an average of four cycles of load-slip/rupture then reload before the peak load value is achieved ( 4.2 and 4.4 cycles, Table 1). This is surprising considering the additional strands placed in the modified sheets. The pre-peak loads sustained by the seismic sheets are typically greater than the standard mesh, with average loads ranging from about 25-60 kN for seismic compared to about $25-40 \mathrm{kN}$ for the standard mesh.

Table 1 Number of pre-peak load cycles for standard mesh (above) and seismic mesh (lower) test data for dice 5 position

\begin{tabular}{|lllllllllll}
\hline \# Load cycles & $\mathbf{1}$ & $\mathbf{2}$ & $\mathbf{3}$ & $\mathbf{4}$ & $\mathbf{5}$ & $\mathbf{6}$ & $\mathbf{7}$ & Max & Sum & Avg \\
\hline \multicolumn{7}{c}{ Standard } \\
\hline
\end{tabular}


Average peak loads sustained by seismic sheets are typically $24 \%$ greater than the standard mesh, at about 50 and $40 \mathrm{kN}$ respectively (Figures 14 and 15). This phenomenon suggests the additional strands accommodate load perhaps progressively, as a collective group of strands. This is at odds with the observed failure modes and the behaviour is not fully understood.

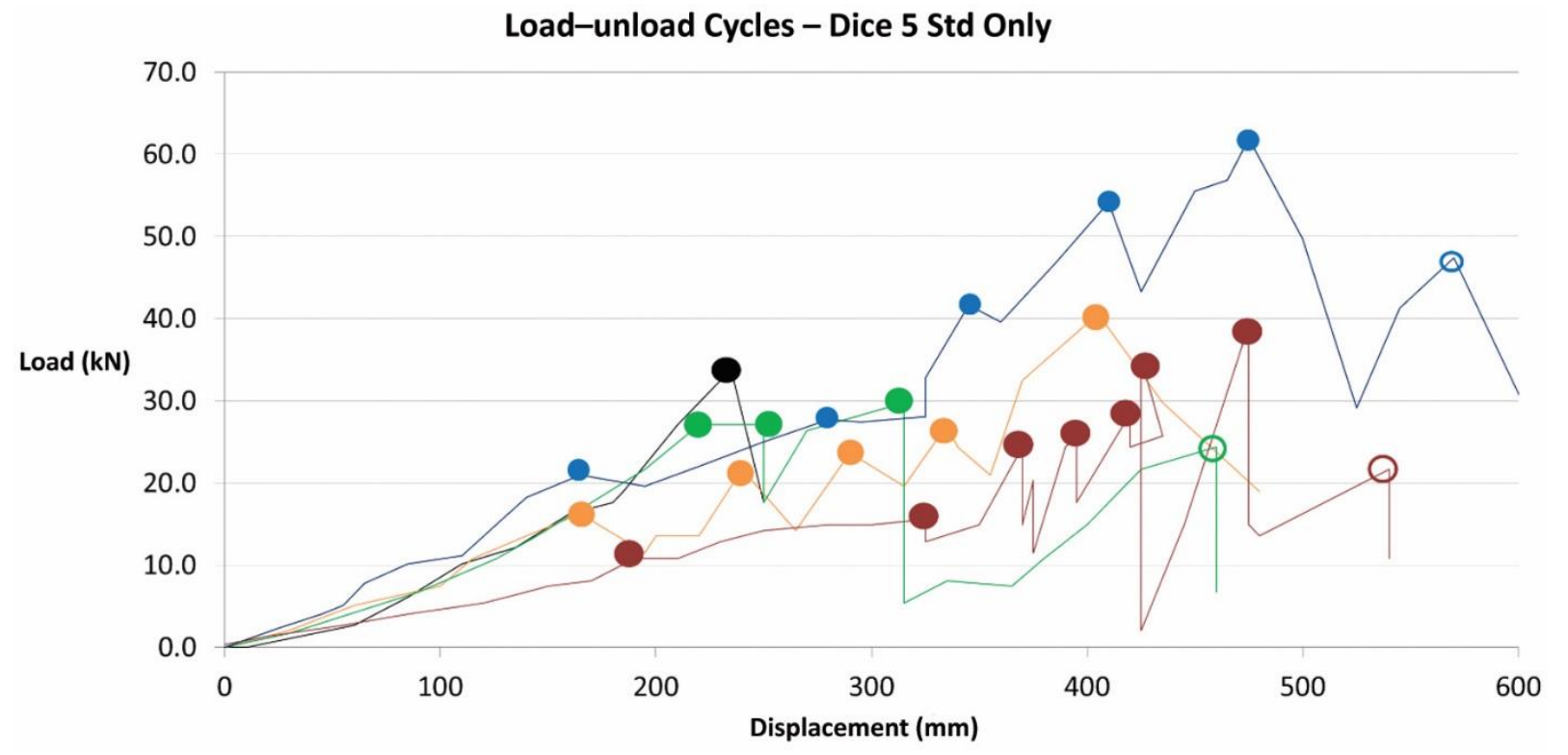

Figure 14 Load cycles showing peak values for Standard mesh tests (solid circles). Open circles are post-peak values

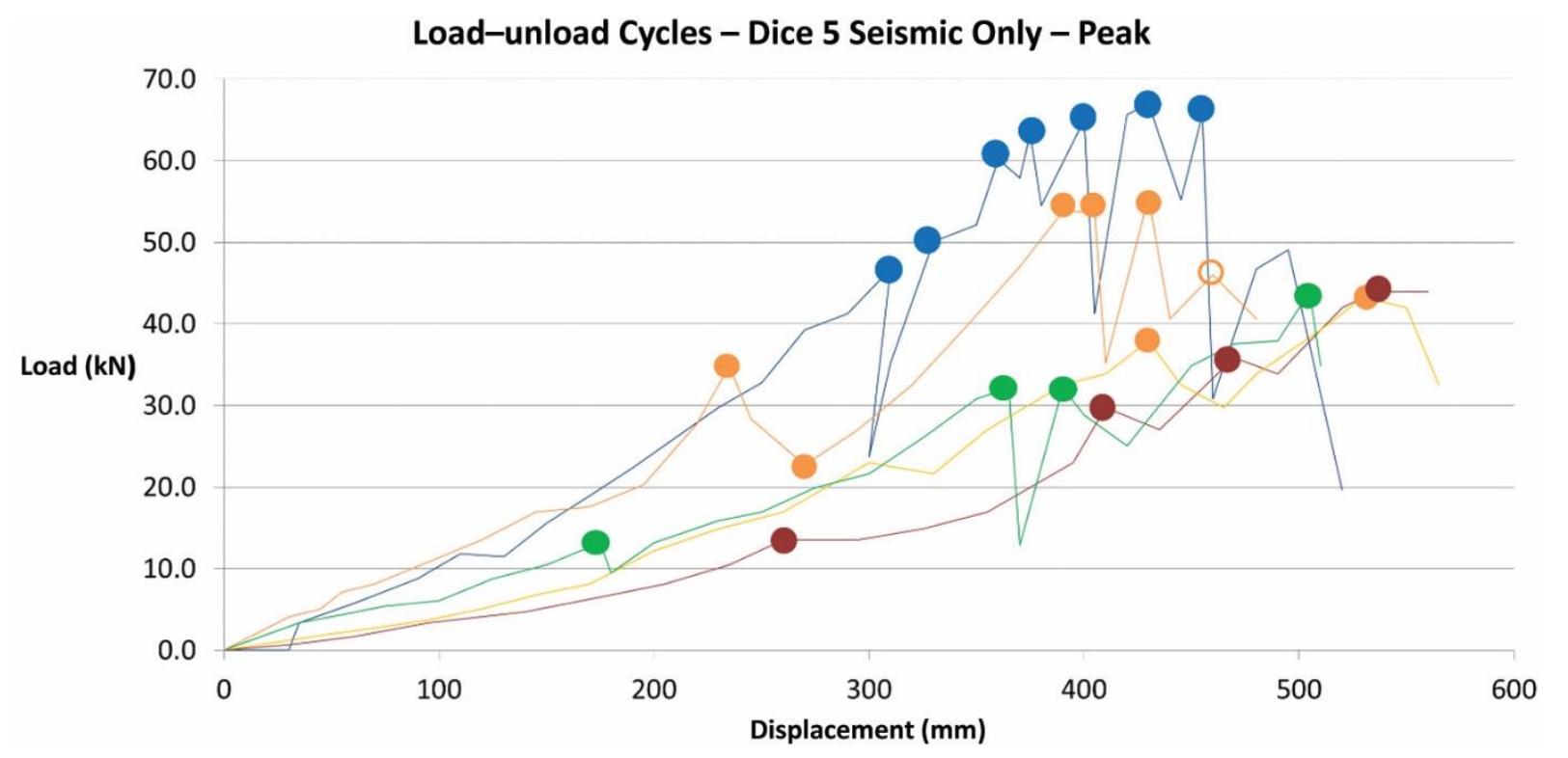

Figure 15 Load cycles showing peak values for seismic mesh tests (solid circles)

In terms of the generalised pre-peak behaviour, the seismic mesh accommodates almost $48 \%$ greater load capacity than the standard mesh. Figure 16 shows point data for all seismic versus all standard dice 5 tests up to the peak load value. The trend line equations show that seismic mesh sustains $48 \%$ greater load per unit of displacement than the standard mesh. 


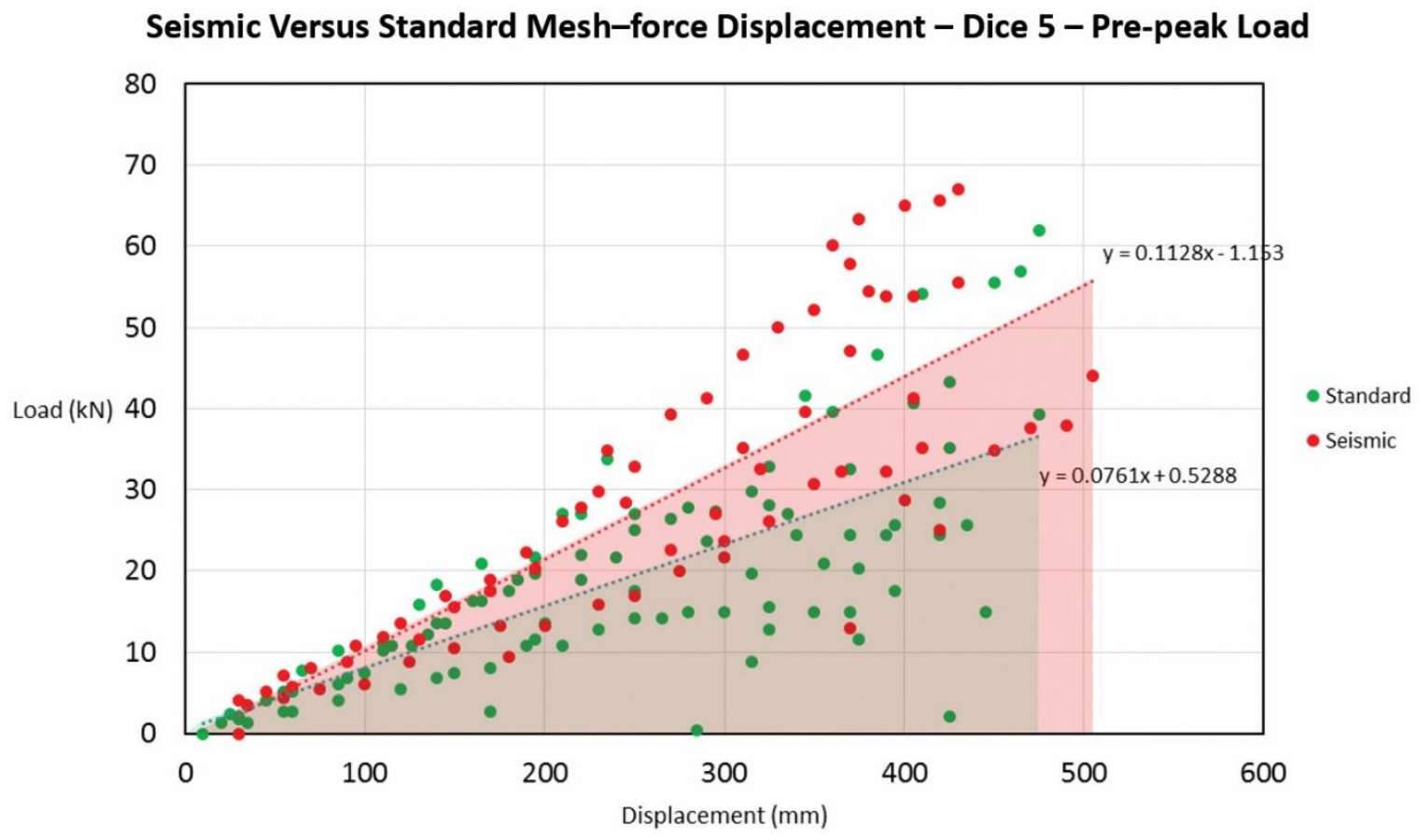

Figure 16 Pre-peak force displacement data points from all seismic and standard sheets show the area under the pre-peak curve. For seismic mesh the load per unit displacement increases at a rate almost $48 \%$ greater than that of the standard mesh

Total energy absorption by the mesh before peak loading during each test cycle was calculated from the area below the pre-peak sections (energy input) of each test curve for each mesh type (Table 2). Seismic mesh tests yield an average energy consumption of $10 \mathrm{~kJ}$ compared to $6 \mathrm{~kJ}$ for the standard mesh. These values are expressed for the nominal $1.4 \mathrm{~m}^{2}$ test panel area. Given that the seismic and standard sheets had a similar number of load peaks and similar displacement range within a test cycle, the higher energy consumption is due to the greater force applied to mobilise the sheet.

Table 2 Total energy mobilised during test cycles calculated from the area below the pre-peak sections of individual test curves

\begin{tabular}{llll}
\hline Standard mesh & $\begin{array}{l}\text { Test cycle total energy } \\
\mathbf{k J}\left(\mathbf{1 . 4} \mathbf{~} \mathbf{~}^{\mathbf{2}} \text { nominal area) }\right.\end{array}$ & Seismic mesh & $\begin{array}{l}\text { Test cycle total energy } \mathbf{~ J} \\
\mathbf{( 1 . 4} \mathbf{~}^{\mathbf{2}} \text { nominal area) }\end{array}$ \\
\hline 160608_Test 2 & 12.5 & 161006_Test 5 & 12.4 \\
\hline 160120_Test 1 & 2.8 & 161006_Test 6 & 9.3 \\
160727_Test 1 & 6.2 & 161006_Test 7 & 10.4 \\
160727_Test 2 & 4.8 & 160310_Test 1 & 8.2 \\
\hline 160728_Test 1 & 5.6 & 160310_Test 2 & 9.8 \\
\hline Average & $\mathbf{6}$ & & $\mathbf{1 0}$ \\
\hline
\end{tabular}

\subsection{Dice 5 configuration tests on shoulder on seismic mesh}

Installation of mesh on a concave surface such as a drive shoulder can reasonably expect to have significantly lower system stiffness than a flat wall installation. Figure 17 shows the mesh on a concave surface must displace a distance where no tensile load is experienced until the sheet displaces sufficiently to come under tension from the bolting pattern. 


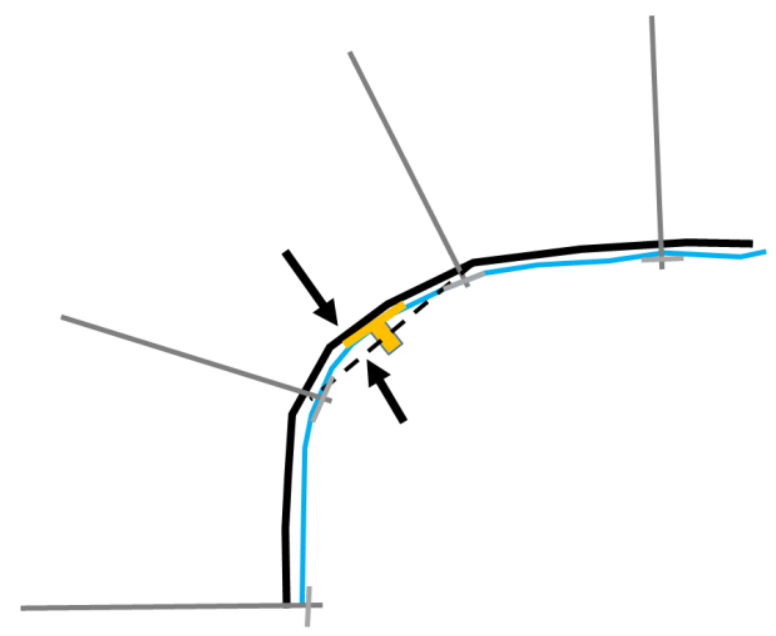

Figure 17 Mesh installation in shoulder of drive

The test data from shoulder installations (Figure 18) shows a significantly lower load increase per unit displacement for these installations relative to wall installations. Strand rupture events for shoulder installations initiate at comparable loads to the wall tests, but substantially greater displacements are required to achieve rupture.

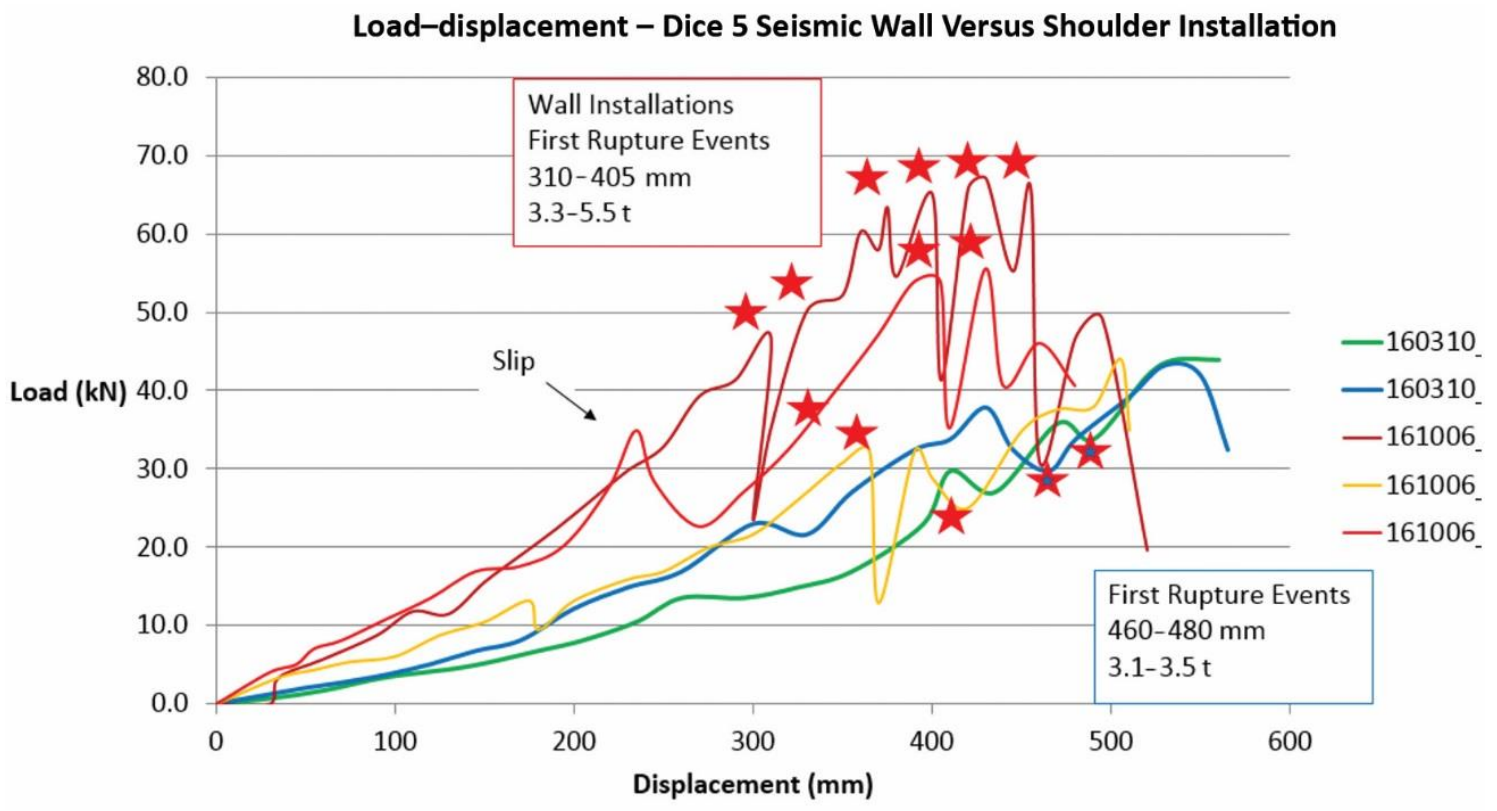

Figure 18 Load-displacement data for dice 5 wall installations in seismic mesh (hot colours) versus drive shoulder installations (cold colours). Note the shoulder installations were not able to be tested to ascertain peak loads as the test equipment did not have sufficient stroke length at the time. It was later modified to increase stroke

Unfortunately the test unit did not have sufficient stroke to complete these tests to destruction at the time, limiting the dataset to two rupture events only.

\subsection{Seismic mesh versus standard mesh - overlap locations - flat walls}

Overlap tests incorporate two layers of mesh overlapping directly in line between rockbolts (Figure 9). The linear distance between restraining bolts and test location is less than for a dice 5 location at 1.1 or $1.3 \mathrm{~m}$ when perfect geometry is achieved (depending on sheet orientation). Figure 19 shows results for seismic and standard mesh tests in overlap locations. Only one test has been completed for standard mesh, making direct comparison limited. 


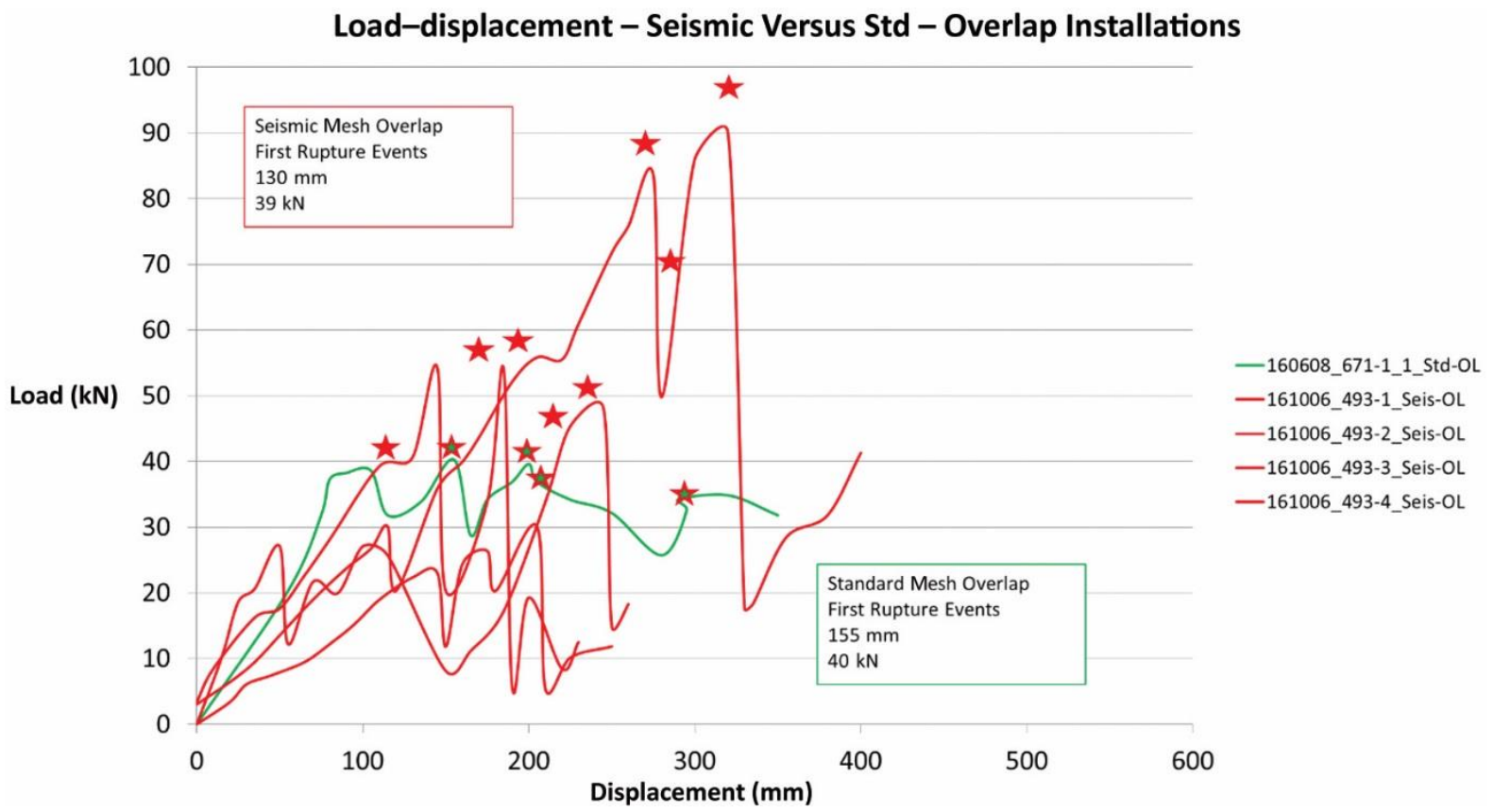

Figure 19 Test results for overlap locations in seismic and standard mesh. Only one test completed for standard mesh (green curve). Stars indicate known rupture points

The available data indicates that strand ruptures initiate at similar load and displacement for both standard and seismic mesh (130-155 mm @ $40 \mathrm{kN}$ ). This represents a far stiffer system than the dice 5 installations, which achieve comparable loads at 200-400 mm displacement. Seismic mesh response curves are far more erratic than the standard mesh. Seismic responses are highly variable with some falling below the standard mesh load capacity and others significantly higher.

In one test the maximum load achieved was $90 \mathrm{kN}$ for seismic mesh (Test 161006_493-4 OL). The load attained in this particular test is far in excess of the majority of the dataset. This is related to the installation geometry. Care was taken (in tests of 161006 series) to achieve correct bolt locations within the mesh sheets. Observations during this test also showed the mesh undergoing a phase of progressive slip behaviour where strands resisted movement under the restraining plate, however not to the point where strand rupture occurred. This behaviour occurred to some degree on both restraining ends of the test panel, allowing the additional strands and larger diameter strands (of both sheets) to be in contact with the restraining bolts concurrently. The resultant high load was therefore shed to the highest capacity sections of the mesh at each restraining bolt at the same time.

This scenario is rarely observed as the sheets often do not line up perfectly, causing one or more corners of the mesh to lock up before all the high capacity strands are in contact with the restraining bolts. This forces another corner to preferentially yield or rupture as load increases.

It therefore seems highly advantageous to place the mesh sheets in a geometrically perfect overlap to allow simultaneous loading of the high capacity strands. It would also benefit to limit the load applied to the restraining bolts within a range which allows progressive slip of the mesh under the plate fixture, at a load which does not exceed the tensile strength of the wire.

Applying those learnings in a practical sense on an operational scale is not a simple task. The loads experienced in that outlier test are, therefore, considered to be at the upper end of that which is practically achievable, and may not represent the majority of site installations.

Further test work is needed on standard mesh overlaps as no comparable data is yet available, but it is unlikely that standard mesh could approach the seismic mesh capacity. 


\section{Discussion}

This work is intended to compliment, not dispute or replace, high quality laboratory data. The different loading mechanisms and real world geometries of the test provide insight and a better understanding of the in situ loading mechanics. The test method outlined does not replicate real world loading of mesh by a rock mass. In particular, the test method does not use geometrically perfect or equal bolt spacing or test plate location. While this adds a degree of complexity or non-uniformity to the results, it is consistent with real world installation and hence considered acceptable and relevant.

Dolinar (2006) outlined the importance of the load applied to bearing plates - "Essentially, slippage of the screen at the bearing plates dominates the screen behaviour and limits the design load." The installed load of the friction bolts in this program is not known as is the case in real world installation conditions.

Similarly, the installations tested represent the real-world 'degrees of freedom' in terms of mesh confinement beyond the sheet boundaries - a point which laboratory test methods do not replicate.

Dice 5 test positions do not necessarily test larger diameter strand capacity. The sheet is free to move so only standard strands are consecutively loaded in preference to larger strands. One would logically expect there to be more load cycles for seismic mesh than standard mesh due to the additional strands in seismic mesh, however, test results do not support this assumption.

The data shows, for a static loading condition, both standard and seismic mesh will fail by successively rupturing individual strands and welds at the locating bolts prior to it failing at the dice 5 load point where no additional strands are present. The same applies to an overlap test location.

Tensile strand rupture has far more significant load drop than weld rupture. Rupture events create a large instantaneous decrease in load capacity. Earlier tests in the program did not show this as well as later testing with a digital gauge where maximum interval pressures could be recorded.

Mesh strand ruptures may initiate around bolts/fixtures away from the unconfined edge of the sheet. An example is presented in Figure 20 where a test at a dice 5 location may first initiate strand ruptures away from the sheet edge. However once strand failure allows the sheet to move sufficiently to apply tension from other fixtures outside the immediate test panel, the failure front migrates to the unconfined outer edge of the sheet (dashed line).

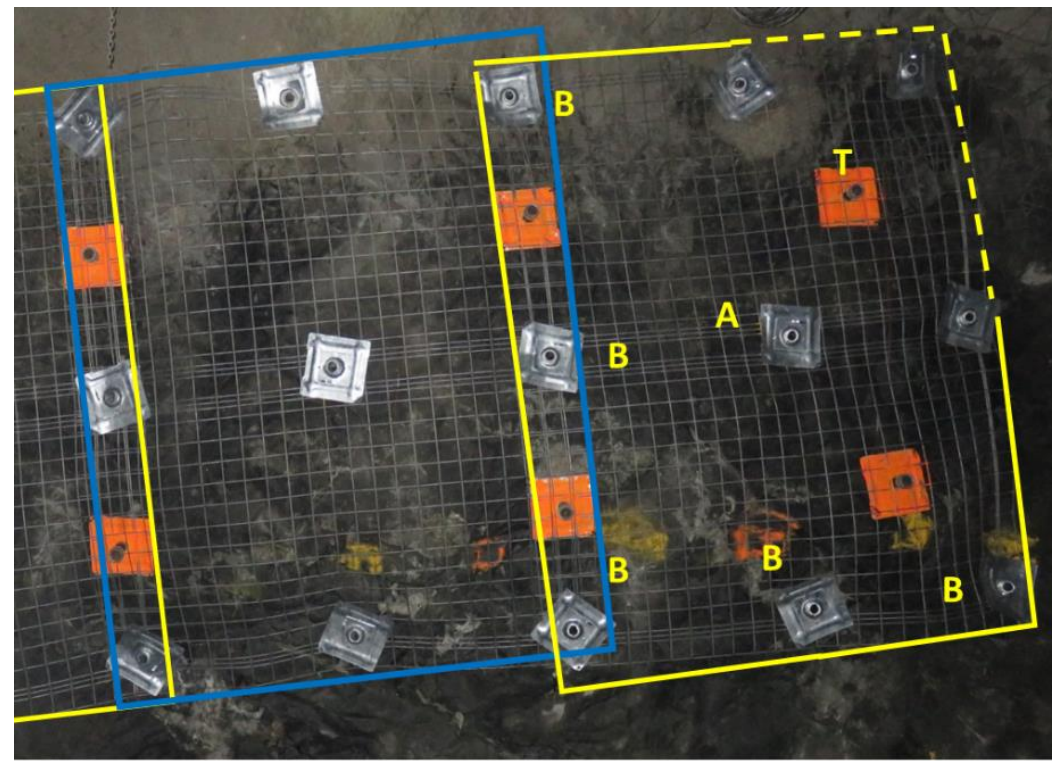

Figure 20 Mesh strand ruptures may initiate around bolts/fixtures away from the edge of the sheet. For example, a test at panel ' $T$ ' may initiate strand ruptures at location ' $A$ '. However, once strand failure allows the sheet to move sufficiently to apply tension from other fixtures outside the test panel (' $B$ '), the failure front migrates to the unconfined outer edge of the sheet (dashed line) 
Dice 5 test locations in both seismic and standard mesh deliver generally linear loading of 250-350 mm displacement before step unloading begins to occur (Figure 21). Standard and seismic mesh are comparable in terms of the number of loading cycles accommodated prior to peak loading. Both have an average of four cycles of load-slip/rupture, then reload before the peak load value is achieved. The average peak loads sustained by seismic sheets are typically $24 \%$ greater than the standard mesh, at about 50 and $40 \mathrm{kN}$ respectively.

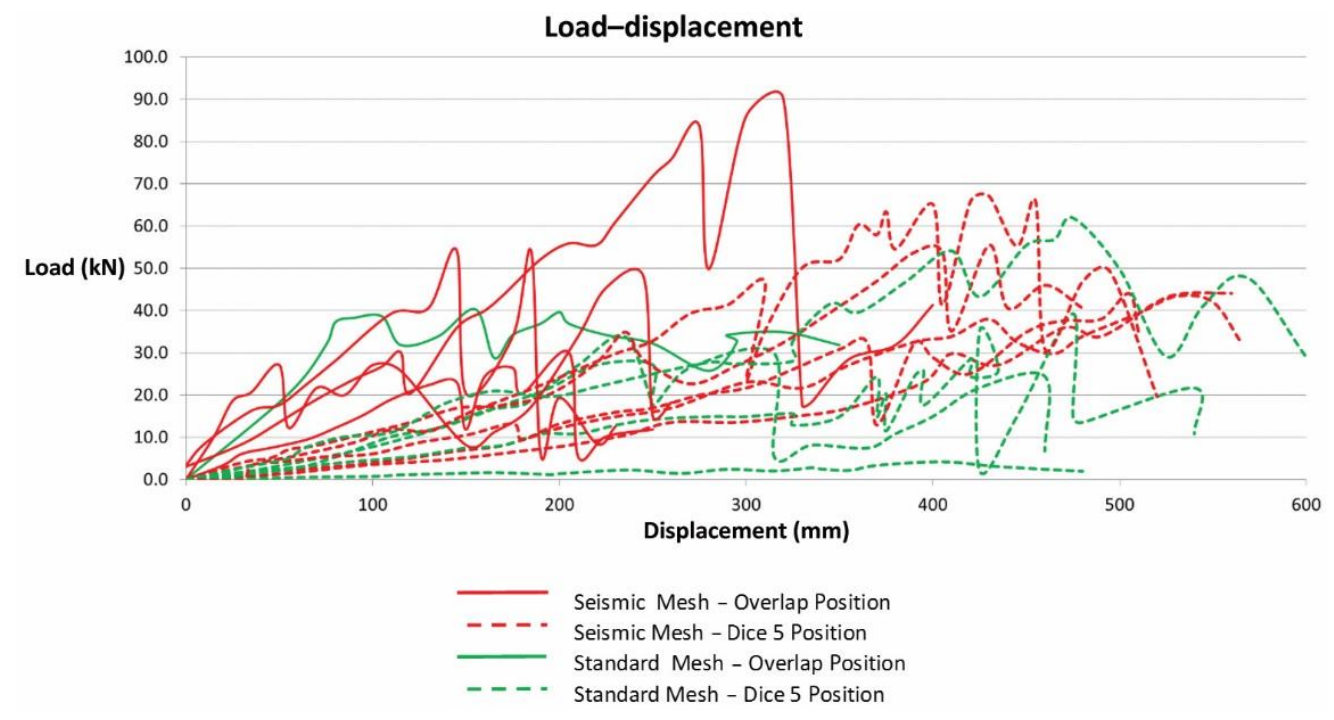

Figure 21 All test data plotted together

Mesh installations in the shoulder of a drive are a softer support scheme than a wall installation. The rock mass in the shoulder locations sees less confinement from support than that in wall or convex locations due to the internal curve of the mesh system. Mesh installed in the shoulder will accommodate greater displacements to achieve comparable load to a wall installation.

The mesh overlap test location is a stiffer section of the support scheme than the dice 5 location. Seismic mesh responses are highly variable with some falling below that of the standard mesh load capacity and others significantly higher.

Generalised pre-peak behaviour of the seismic mesh accommodates almost $48 \%$ greater load capacity than the standard mesh.

Seismic mesh tests yield an average energy consumption $24 \%$ greater than standard sheets at $10 \mathrm{~kJ}$ compared to $6 \mathrm{~kJ}$ for the standard mesh, expressed for the nominal $1.4 \mathrm{~m}^{2}$ test panel area.

\section{Conclusion}

- For a static loading condition, both standard and seismic mesh will fail by successively rupturing individual strands and welds at the locating bolts prior to it failing at the dice 5 load point. The same applies to an overlap test location.

- Tensile strand rupture results in far more significant load drop than weld rupture.

- Standard and seismic mesh are comparable in terms of the number of loading cycles accommodated prior to peak loading. However, the average peak loads sustained by seismic sheets in a dice 5 test geometry are typically $24 \%$ greater than the standard mesh, at about 50 and $40 \mathrm{kN}$ respectively.

- The trend line loading rate equations show seismic mesh sustains $48 \%$ greater load per unit of displacement than the standard mesh.

- Seismic mesh tests yield an average energy consumption $24 \%$ greater than standard sheets at $10 \mathrm{~kJ}$ compared to $6 \mathrm{~kJ}$ for the standard mesh, expressed for the nominal $1.4 \mathrm{~m}^{2}$ test panel area. 


\section{Acknowledgement}

The author thanks Lee Horan, Independence Group, Rocktech Pty Ltd, Peter Mikula, Australian Steel and Wire and Kyle Williams for their assistance in data collection and interpretation, and IGO Long Operations for permission to publish the work.

\section{References}

Dolinar, D 2006, 'Load capacity and stiffness characteristics of screen materials used for surface control in underground coal mines', in SS Peng (ed), Proceedings of the 25th International Conference on Ground Control in Mining, 1-3 August 2006, Morgantown, National Institute for Occupational Safety and Health (US), United States Mine Safety and Health Administration, West Virginia Coal Association, West Virginia University.

Morton, E, Thompson, A, Villaescusa, E \& Roth, A 2007, 'Testing and analysis of steel wire mesh for mining applications of surface rock support', Proceedings of the 11th Congress of the International Society for Rock Mechanics, vol. 2, 9-13 July 2007, L Ribeiro e Sousa, C Olalla \& N Grossman (eds), International Society for Rock Mechanics, Lisboa, pp. 1061-1064.

Player, JR, Morton, EC, Thompson, AG \& Villaescusa, E 2008, 'Static and dynamic testing of steel wire mesh for mining applications of rock surface support', Proceedings of the 6th International Symposium on Ground Support in Mining and Civil Construction, Southern African Institute of Mining and Metallurgy, Johannesburg, pp. 693-706.

Tannant, DD 1995, 'Load capacity and stiffness of welded wire mesh', Proceedings of the 48th Canadian Geotechnical Conference, Canadian Institute of Mining, Metallurgy and Petroleum, Westmount, pp. 729-736.

Thompson, AG, Windsor, CR \& Cadby, GW 1999, 'Performance assessment of mesh for ground control applications', in E Villaescusa, CR Windsor \& EC Thompson (eds), Rock Support and Reinforcement Practice in Mining, Balkema, Rotterdam, pp. 119-130. 